\title{
КОНЦЕПЦИЯ УПРАВЛЕНИЯ СОЦИАЛЬНЫМ ПРЕДПРИНИМАТЕЛЬСТВОМ В СОЮЗНОМ ГОСУДАРСТВЕ БЕЛАРУСИ И РОССИИ
}

\begin{abstract}
Аннотация. Становление и развитие сочиального предпринимательства в Союзном го-
\end{abstract} сударстве предполагает выработку согласованных мер по формированию перспективной модели организачионно-экономического механизма регулирования деятельности субъектов социального предпринимательства. Создание условий для эффективного функционирования субъектов сочиального предпринимательства в Союзном государстве предполагает не только разработку нормативно-правовой базы для Республики Беларусь и Российской Федераџии, но и содействие в занятости сочиально незащищённых слоёв населения, решение сочииальных проблем и достижение соииальных иелей Союзного государства. В основу формирования методологии управления сочиальным предпринимательством в Союзном государстве должен быть положен унифицированный категориальный аппарат для однозначной интерпретации понятий, принятие единой методики для оченки деятельности субъектов социального предпринимательства, т.е. создание общей концепщии управления.

Ключевые слова: Социальное предпринимательство, управление сочииальным предпринимательством, трудоустройство сочиально незащцищённых слоёв населения, Союзное государство.

Создание условий для эффективного функционирования субъектов социального предпринимательства в Союзном государстве предполагает не только разработку нормативно-правовой базы для Республики Беларусь и Российской Федерации, но и содействие в занятости социально незащищённых слоёв населения, решение социальных проблем и достижение социальных целей Союзного государства.

В основу формирования методологии управления социальным предпринимательством в Союзном государстве должен быть положен унифицированный категориальный аппарат для однозначной интерпретации понятий, принятие единой методики для оценки деятельности субъектов социального предпринимательства, т.е. создание общей концепции управления.

\section{Развитие социального предпринимательства в странах союзного государства}

Социальное предпринимательство является одним из самых динамично развивающихся направлений деятельности во всём мире. Отдельные проявления социального предпринимательства можно было наблюдать в Европе в XIX в. и в Азии в первой половине XX в. ${ }^{1}$ В странах СНГ данный экономический феномен начал развиваться меньше десятилетия назад. Однако до сих пор нет методологического единства в вопросах определения данного экономического термина, идентификации его критериев и расчёта показателей.

Существует точка зрения, что социальное предпринимательство - это деятельность ру-

\footnotetext{
(C) Краенкова Кристина Игоревна - старший преподаватель УО «Витебский государственный технологический университет». Aдpec: 210038, Республика Беларусь, г. Витебск, пр-т Московский 74. E-mail: kristina-zhavrnk@rambler.ru.
}

DOI: http://dx.doi.org/10.15211/vestnikieran32019140147

${ }^{1}$ Юнус М., Жоли А. Создавая мир без бедности. Социальный бизнес и будущее капитализма, М., 2009. С. 58. 
ководителей, которые уделяют всё больше внимания реалиям рынка, не упуская при этом из виду свою основную социальную миссию ${ }^{1}$.

Российские авторы трактуют социальное предпринимательство как одно из перспективных направлений развития малого и среднего бизнеса, способствующее решению многих социальных проблем, содействующее расширению спектра социальных услуг и трудоустройству незащищённых слоёв населения ${ }^{2}$. Так, И.В. Манахова утверждает, что социальное предпринимательство - это предпринимательская деятельность, направленная на смягчение или решение социальных проблем³.

Таким образом, социальное предпринимательство можно определить как вид предпринимательской деятельности, направленный на инновационное решение социальных проблем или достижение социальных целей ${ }^{4}$.

Отсутствие в практике хозяйствования единого подхода к определению социального предпринимательства, как в мировой практике, так и в Российской Федерации и в Республике Беларусь, препятствует операционализации данного явления и ограничивает его развитие. Решением данной проблемы может стать разработка организационно-экономического механизма регулирования деятельности социального предпринимательства.

В РФ широкое развитие социального предпринимательства началось в 2007 г. с открытием Фонда региональных программ «Наше будущее», который является главной информационной и финансовой поддержкой субъектов социального предпринимательства. Функционирующий на территории России портал «Банк социальных идей» отвечает за информирование о субъектах социального предпринимательства и ежегодно публикует каталог субъектов социального предпринимательства ${ }^{5}$.

В Российской Федерации продвижением социального предпринимательства занимаются как на государственном, так и частном уровнях. Об этом свидетельствует, с одной стороны, развитая инфраструктура: организована и налажена работа по всей стране образовательных и научно-исследовательских структур, фондов поддержки уже функционирующих субъектов социального предпринимательства, а также стартапов; с другой стороны - системная поддержка субъектов социального предпринимательства через региональные власти (согласно приказу Минэкономразвития России № 220 от 24.04.2013 г. созданы центры инноваций социальной сферы, в соответствии с постановлением Правительства Российской Федерации от 23.08.2011 г. № 713 «О предоставлении поддержки социально ориентированным некоммерческим организациям» выдаются субсидии).

Закон о социальном предпринимательстве в РФ был одобрен на «нулевом чтении» в Государственной Думе в декабре 2018 г. Предложенный законопроект предполагает выделить субъекты социального предпринимательства в отдельный сектор экономики и закрепить следующие понятия в категорийном аппарате: «социальное предпринимательство» и «социальное предприятие».

Предложенный вариант законопроекта предполагает внедрение критериев по идентификации субъектов социального предпринимательства, а также определяет виды адресной госу-

\footnotetext{
${ }^{1}$ Boschee J. Merging Italicssion and money: A board member'sguide to social entrepreneurship, USA: The National Center for Nonprofit Boards. 2018. P. 118.

${ }^{2}$ Гурина А.В. Проблемы социального предпринимательства в России и пути его реформирования. Актуальные проблемы права: материалы IV междунар. науч. конф. (г. Москва, ноябрь 2015 г.), М., Буки-Веди, 2015. С. 91.

3 Манахова И.В. Социальное предпринимательство как экономическое явление. Вестник ПАГС, №4, 2011. 170.

${ }^{4}$ Ванкевич Е.В., Краенкова К.И. Социальное предпринимательство в современных условиях: сущность и методы оценки. Вестник БГЭУ, №2, 2018. С. 10.

5 Официальный портал «Банк социальных идей. URL: http://www.social-idea.ru/ (дата обращения: 18.04.2018).
}

Научно-аналитический вестник ИЕ РАН, 2019, №3 
дарственной поддержки субъектам социального предпринимательства.

В Республике Беларусь субъекты социального предпринимательства не выделены в отдельный сектор экономики. Для получения объективного мнения о количестве и направлениях функционирования организаций проводится ряд исследований. В 2016 г. ОДБ Брюссель был проведён мониторинг ${ }^{1}$, по результатам исследования которого составлен каталог субъектов социального предпринимательства. Так, в большинстве организаций, включённых в него, работают люди с ограниченными возможностями. В Республике Беларусь созданы Общественные Объединения «Белорусское общество глухих», «Белорусское товарищество инвалидов по зрению» и «Белорусское общество инвалидов», которые содействуют занятости данной категории граждан.

Таким образом, в Республике Беларусь реализуется следующая адресная поддержка субъектам социального предпринимательства:

- налоговые льготы при трудоустройстве людей с ограниченными возможностями;

- рыночная интеграция в виде государственных закупок при трудоустройстве людей с ограниченными возможностями.

В настоящее время в Республике Беларусь формируется взаимосвязь между субъектами социального предпринимательства и государственными, общественными объединениями. В республике проводятся форумы, круглые столы, на которых обсуждаются вопросы социального предпринимательства. Например, первое консалтинговое учреждение «Социальные технологии бизнеса» консультирует по вопросам создания и развития субъектов социального предпринимательства. В 2017 г. НИИ труда Министерства труда и социальной защиты Республики Беларусь предпринял попытку разработать документ, регламентирующий правовые основы социального предпринимательства в стране. Однако в целом инфраструктура поддержки субъектов социального предпринимательства ещё не сформирована.

Таким образом, становление социального предпринимательства в странах Союзного Государства России и Беларуси отличается высоким динамизмом, что характеризуется определённым уровнем продвижения и развития (табл. 1).

\section{Сравнительная характеристика уровня продвижения и развития} социального предпринимательства

\begin{tabular}{|l|c|c|}
\hline \multicolumn{1}{|c|}{ Критерии } & Российская Федерации & Республика Беларусь \\
\hline по уровню правового обеспечения & на стадии утверждения & на стадии разработки \\
\hline по трудоустройству & разные категории граждан & разные категории граждан \\
\hline по степени поддержки государства & $\begin{array}{c}\text { налоговые преференции, субсиди- } \\
\text { рование субъектов }\end{array}$ & $\begin{array}{c}\text { налоговые преференции имеют субъ- } \\
\text { екты, в которых трудоустроены люди } \\
\text { с ограниченными возможностями }\end{array}$ \\
\hline $\begin{array}{l}\text { по степени поддержки частных } \\
\text { структур }\end{array}$ & $\begin{array}{c}\text { консультационные услуги, воз- } \\
\text { можность получение субсидий, } \\
\text { беспроцентных займов }\end{array}$ & консультационные услуги \\
\hline по способу создания & $\begin{array}{c}\text { организация фандрайзинговой и } \\
\text { краудфандинговой кампании, с } \\
\text { помощью учредителей (спонсоров) }\end{array}$ & $\begin{array}{c}\text { организация фандрайзинговой и кра- } \\
\text { уандовой кампании, с помощью } \\
\text { учредителей (спонсоров) }\end{array}$ \\
\hline по уровню продвижения & более 40 видов экономической \\
деятельности & $\begin{array}{c}\text { более 20 видов экономической дея- } \\
\text { тельности }\end{array}$ \\
\hline по узнаваемости в обществе & низкий уровень & низкий уровень \\
\hline
\end{tabular}

Анализ позволил сделать вывод, что факторами, способствующими развитию социального предпринимательства, в Республике Беларусь и в Российской Федерации являются активная политика в области становления социального предпринимательства, создание благоприятной среды для представительства интересов субъектов социального предприниматель-

\footnotetext{
${ }^{1}$ Официальный портал ОДБ Брюссель. URL: https://by.odb-office.eu/ (дата обращения: 16.02.2018). Научно-аналитический вестник ИЕ РАН, 2019, №3
} 
ства в государственных и частных структурах, где есть реальная возможность получения финансирования проектов.

При этом в настоящий момент времени ни в одной из стран не разаработан единый механизм функционрования субъектов социального предпринимательства, нет унификации в категориальном аппарате, что является барьерами для более прогрессивного развития и закрепления данных субъектов предпринимательства в правовой базе. Объединение усилий и опыт каждой из страны позволит разработать единую концепцию управления социальным предпринимательством посредством разработки организационно-экономического механизма регулирования деятельности данных экономических единиц.

\section{Основные направления политики в области управления социальным предпринимательством в союзном государстве}

Основные принципы и направления формирования основ управления социальным предпринимательством в Союзном государстве были сформулированы на основе концепции социального развития Союзного государства на 2011-2015 гг. ${ }^{1}$

Для институализации социального предпринимательства и закрепления деятельности его субъектов на законодательном уровне необходимо разработать концепцию управления социальным предпринимательством в Союзном государстве.

Цель концепции - разработка организационно-экономического механизма управления для повышения эффективности функционирования субъектов социального предпринимательства.

Достижение поставленной цели предполагает реализацию следующих задач:

- решение социальных проблем и достижение социальных целей политики Союзного государства;

- содействие занятости социально незащищенных слоев населения;

- расширение возможностей трудовой активности для лиц с ограниченными возможностями;

- предотвращение маргинализации разных социальных групп;

- содействие снижению институциональных барьеров для развития нестандартных форм занятости;

- операционализация понятия «социально предпринимательство»;

- создание законодательной базы, разработка льгот и преференций для субъектов социального предпринимательства.

Реализация данной концепции на уровне Союзного годарства даст более значимый результат в становлении социального предпринимательства, чем в отдельности по каждой стране. Это, в первую очередь, связано с расширением границ и возможностей функционирования субъектов социального предпринимательства.

Приоритетами политики Союзного государства в области управления социального предпринимательства являются:

- усиление взаимодействия и консолидация усилий в области развития социального предпринимательства на территории государств;

- проведение согласованной социальной политики, направленной на создание условий, обеспечивающих достойную жизнь всем категориям граждан;

- содействие занятости социально незащищенных слоёв населения, их территориальной

\footnotetext{
${ }^{1}$ Концепция социального развития Союзного государства на 2011-2015 годы, утверждена Постановлением Высшего Государственного Совета Союзного государства. 25.11.2011. №7.
}

Научно-аналитический вестник ИЕ РАН, 2019, №3 
мобильности;

- институциональное становление социального предпринимательства в Союзном государстве;

- создание дополнительных рабочих мест для людей с ограниченными возможностями, их интеграция в общество.

Основные этапы развития социального предпринимательства в Союзном государстве представлены на рисунке 1.

\section{Этапы развития социального предпринимательства в Союзном государстве}

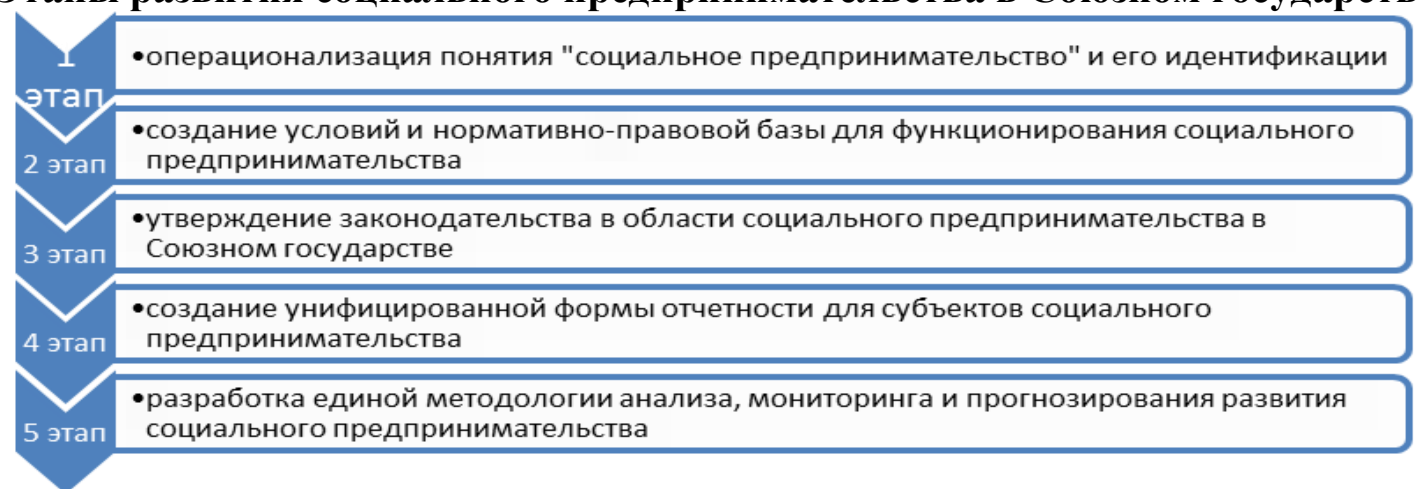

В настоящий момент в России согласно законопроекту, принятому в «нулевом» чтении, к субъектам социального предпринимательства можно отнести организации, которые:

- способствуют занятости социально незащищённой категории граждан, при этом в среднесписочной численности их доля должна быть не менее 50\% и доля заработной платы в фонде оплаты труда - не менее $25 \%$;

- обеспечивают доступ к рынку продукцию, работы, услуги, которые произвели или оказали социально незащищённые слои населения.

Следовательно, первый этап в развитии социального предпринимательства успешно выполнен в Российской Федерации и может быть применён в Республике Беларусь.

Реализация второго этапа в РФ ведётся с 2014 г., в Республике Беларусь с 2017 г. Однако успешная их реализация, которая приведёт к созданию условий и нормативно-правовой базы в области социального предпринимательства, может быть достигнута лишь при взаимодействии и обмену опытом среди стран участниц Союзного государства.

Следовательно, объединение усилий может ускорить институализацию данного экономического явления.

Для успешной реализации 2 этапа в Союзном государстве необходимо делегировать определённые функции и полномочия рабочему органу Союзного государства - Постоянному Комитету, в частности Департаменту социальной политики и информационного обеспечения.

Делегирование определённых функций и полномочий Департаменту, позволит успешно реализовать все этапы развития социального предпринимательства в Союзном государстве на разных уровнях, таких так:

- микроуровень, т.е. уровень организации, когда отдельные организации вступают в прямые хозяйственные связи по найму социально-незащищенных слоёв населения, их переподготовке и интеграции; решаются социальные проблемы и достигаются социальные цели собственными силами, т.е. функционирования на принципе самофинансирования и самоокупаемости при незначительной поддержке государства; 
- региональный уровень, т.е. развитие интеграционных связей области социального предпринимательства между регионами России и Беларуси. Это станет возможно при закреплении официального статуса субъектов социального предпринимательства, создания филиалов, партнёрства между функционирующими субъектами социального предпринимательства, обмену опытом;

- национальный уровень предполагает целенаправленную деятельность Российской Федерации и Республики Беларусь в направлении унификации законодательства в области социального предпринимательства;

- наднациональный уровень, когда страны участницы добровольно передают органам Союзного государства ряд функций по организационно-экономическому регулированию вопросов создания, функционирования, развития социального предпринимательства.

На рисунке 2 (см. ниже) представим модель организационно-экономического механизма регулирования и направления деятельности субъектов социального предпринимательства (далее СП) в Союзном государстве. Таким образом, предложенная модель организационно-экономического механизма позволит реализовать цель концепции управления социальным предпринимательством и решить поставленные задачи, что является приоритетным для развития социального предпринимательства в Союзном государстве.

\section{Заключение}

Предложенная концепция управления социальным предпринимательством в Союзном государстве позволит закрепить новый вид деятельности - «социальное предпринимательство», что будет способствовать решению многих социальных проблем и достижению социальных целей не только Союзного государства, но и в отдельности Российской Федерации и Республики Беларусь, что является приоритетными направлениями политики обеих стран.

Предложенная концепция управления социальным предпринимательством позволила разработать модель организационно-экономического механизма, реализация которой позволит эффективно функционировать субъектам социального предпринимательства с закреплением их статуса в законодательной базе. Расширение границ функционирования субъектов социального предпринимательства позволит расширить границы их деятельности, успешно развивать и занимать конкурирующие позиции на рынках стран участниц. 


\section{Модель организационно-экономического механизма управления деятельностью} субъектов социального предпринимательства (составлено автором)

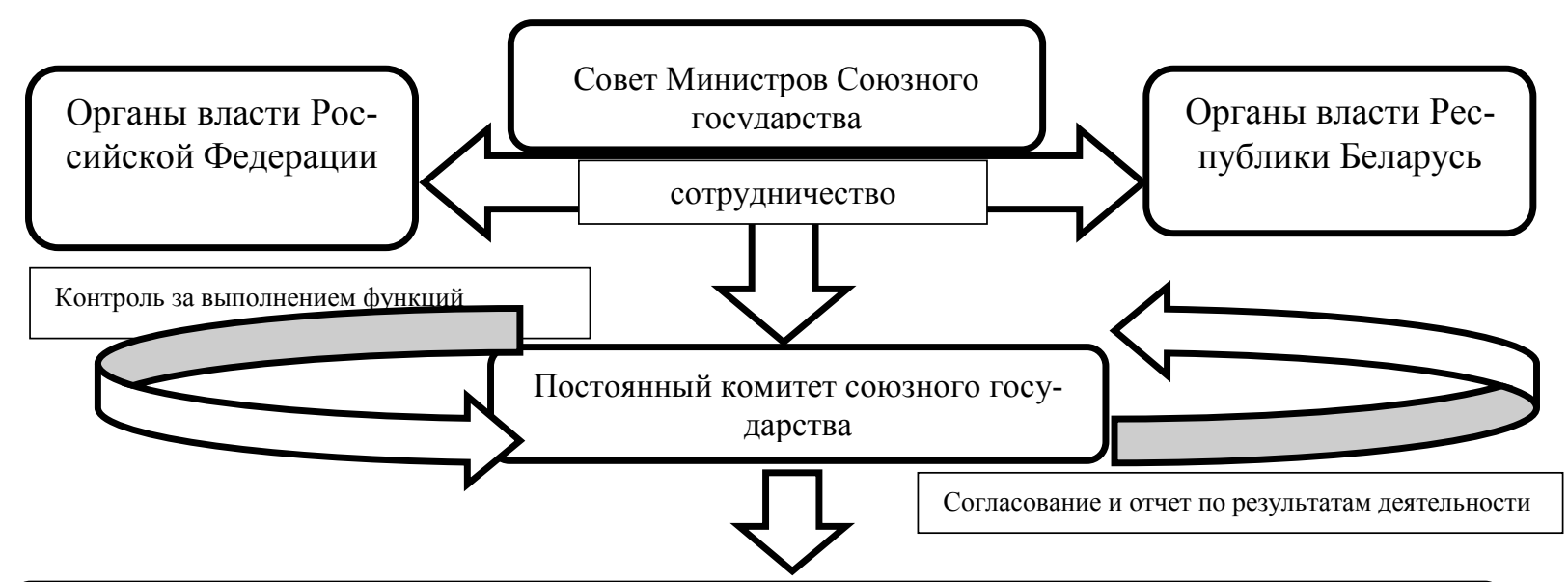

Департамент социальной политики и информационного обеспечения

Организационный механизм

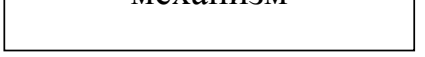

\begin{tabular}{c} 
Качественная оценка: \\
классификация субъек- \\
тов СП \\
\hline
\end{tabular}

Единая идентификация субъектов СП
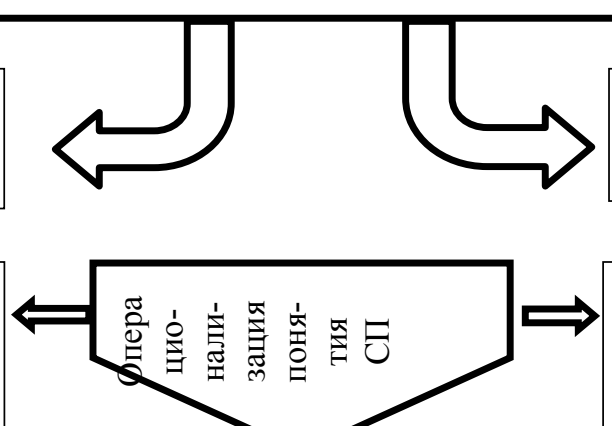

Количественная оценка: расчет уровня социализации бизнеса

\section{Экономический} механизм

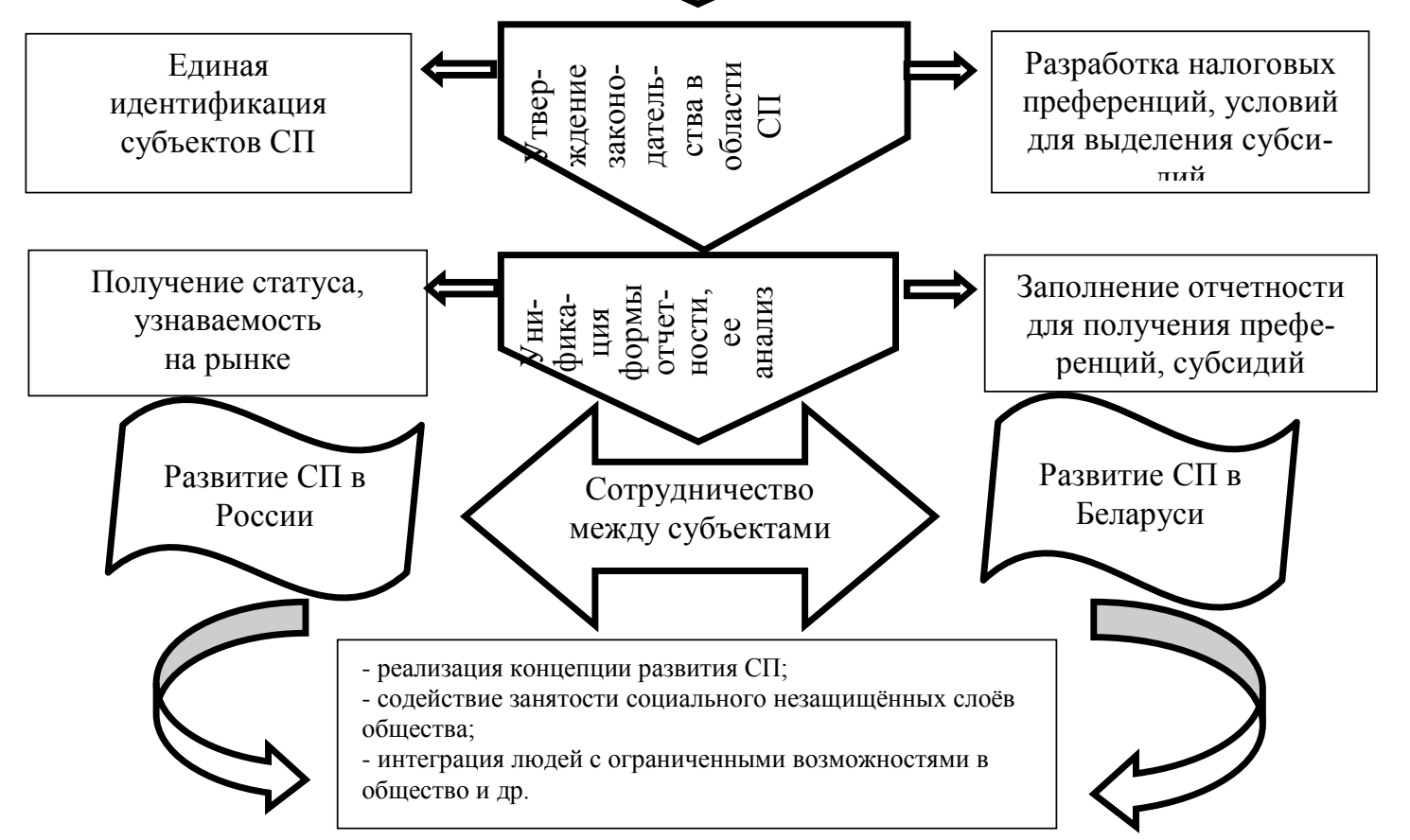

Научно-аналитический вестник ИЕ РАН, 2019, №3 


\section{Список литературы}

Ванкевич Е.В., Краенкова К.И. Социальное предпринимательство в современных условиях: сущность и методы оценки. Вестник БГЭУ, №2, 2018.

Гурина А.В. Проблемы социального предпринимательства в России и пути его реформирования. Актуальные проблемы права: материалы IV междунар. науч. конф. (г. Москва, ноябрь 2015 г.). М., Буки-Веди. 2015.

Концепция социального развития Союзного государства на 2011-2015 годы. Утверждена Постановлением Высшего Государственного Совета Союзного государства. 25.11.2011, №7.

Манахова И.В. Социальное предпринимательство как экономическое явление. Вестник ПАГС, №4, 2011.

Официальный портал фонда «Наше будущее». URL: http://www.nb-fund.ru/ (дата обращения: 18.04.2018).

Официальный портал «Банк социальных идей. URL: http:// www.social-idea.ru/ (дата обра-щения: 18.04.2018).

Официальный портал ОДБ Брюссель. URL: https://by.odb-office.eu/ (дата обращения: 16.02.2018). 2009.

Юнус М., Жоли А. Создавая мир без бедности. Социальный бизнес и будущее капитализма. М.,

\section{References}

Vankevich E.V., Krayenkova K.I. Social'noe predprinimatel'stvo v sovremennyh uslovijah: sushhnost' i metody ocenki. Vestnik BGJeU, №2, 2018.

Gurina A.V. Problemy social'nogo predprinimatel'stva v Rossii i puti ego reformirovanija. Aktual'nye problem prava: materialy $\mathrm{IV}^{\text {th }}$ mezhdunar. nauch. konferentsii (Moscow, November 2015). M., Buki-Vedi, 2015.

Koncepcija social'nogo razvitija Sojuznogo gosudarstva na 2011-2015 gody. Approved by the Resolution of the Supreme State Council of the Union State.25.11.2011, №7.

Manakhova I.V. Social'noe predprinimatel'stvo kak jekonomicheskoe javlenie. Vestnik PGAS, №4, 2011.

Oficial'nyj portal fonda «Nashe budushhee». URL: http://www.nb-fund.ru/ (дата обращения: 18.02.2018).

Oficial'nyj portal «Bank social'nyh idej». URL: http://www.social-idea.ru/ (дата обращения: 18.02.2018).

Oficial'nyj portal ODB Brjussel'. URL: https://by.odb-office.eu/ (дата обращения: 16.02. 2018).

Yunus M., Joly A. Sozdavaja mir bez bednosti. Social'nyj biznes i budushhee kapitalizma, M., 2009.

\section{Social entrepreneurship in the Union State of Belarus and Russia: the concept of management and directions of development}

Author. Kristina Krayenkova, Senior Lecturer of the Department of Economics, Vitebsk State Technological University. Address: Republic of Belarus, Vitebsk, Moskovsky Avenue 74, 210038. E-mail: kristinazhavrnk@rambler.ru.

Abstract. Formation and development of social entrepreneurship in the Union State involves the development of coordinated measures for the formation of a prospective model of the organizational and economic mechanism for regulating the activities of social entrepreneurship entities. The creation of conditions for the effective functioning of the subjects of social entrepreneurship in the Union State implies not only the development of a regulatory and legal framework for the Republic of Belarus and the Russian Federation, but also the employment of socially unprotected sections of the population, the solution of social problems and the achievement of the social goals of the Union State. The basis for the formation of a methodology for managing social entrepreneurship in the Union State should be a unified categorical apparatus for unambiguous interpretation of concepts, the adoption of a unified methodology for assessing the activities of subjects of social entrepreneurship, i.e., the creation of a general management concept.

Keywords: social entrepreneurship, social entrepreneurship management, Union State

DOI: http://dx.doi.org/10.15211/vestnikieran32019140147 